DOI: https//doi.org/......./mirlamvol1nolhlm103-120

\title{
CAMPUR KODE DALAM INTERAKSI JUAL BELI DI PASAR YOTOWAWA-WONRELI KECAMATAN PULAU-PULAU TERSELATAN KABUPATEN MALUKU BARAT DAYA
}

\author{
Elsa Juned Sarik \\ Thomas Frans \\ Petrus Jacob Pattiasina \\ Universitas Pattimura \\ e-mail: Sarikelsajuned@yahoo.com
}

\begin{abstract}
Abstrak: Tujuan penelitian ini adalah untuk mendeskripsikan campur kode dalam interaksi jual beli di pasar Yotowawa Kecamatan PulauPulau Terselatan Kabupaten Maluku Barat Daya. Rancangan penelitian ini bersifat deskriptif kualitatif, karena sesuai dengan tujuan penelitian ini adalah untuk mendeskripsikan campur kode dalam interaksi di pasar Yotowawa desa Wonreli Kecamatan Pulau-Pulau Terselatan Kabupaten Maluku Barat Daya. Hasil penelitian ini adalah dalam penggunaan bahasa di pasar terjadi campur kode (code mixing). Campur kode yang terdapat dalam interaksi komunikasi jual-beli, yaitu campur kode intern pada unsur kata dan struktur frasa. Faktor penyebab penjual dan pembeli menggunakan campur kode dari bahasa Malayu Ambon yang disisipi dengan tutur bahasa Meher. Hal ini terjadi karena antara pembeli dan penjual sama-sama menggunakan tuturan bahasa Malayu Ambon maupun bahasa Meher.
\end{abstract}

Kata Kunci: campur, kode, bahasa 


\title{
MIXING CODE IN BUYING INTERACTION IN YOTOWAWA- WONRELI MARKET, DISTRICT, ISLANDS IN SOUTH MALUKU DISTRICT, WEST MALUKU
}

\author{
Elsa Juned Sarik \\ Thomas Frans \\ Petrus Jacob Pattiasina \\ Pattimura University \\ e-mail: Sarikelsajuned@yahoo.com
}

\begin{abstract}
The purpose of this study is to describe the code mix in the sale and purchase interactions in the Yotowawa market in the SouthEast Islands District of Southwest Maluku. The design of this study is descriptive qualitative, because in accordance with the purpose of this study is to describe the mixed code in the interaction in the Yotowawa market Wonreli village District Terselatan Island Southwest Maluku Regency. The results of this study are that in the use of language on the market there is code mixing. Mix the code contained in the interaction of buying and selling communication, i.e. the internal code mix in the word elements and phrase structure. Factors causing sellers and buyers to use mixed codes from the Malay Malay language which are interleaved with Meher speech. This happens because both buyers and sellers use the Malay Malay and Meher languages.
\end{abstract}

Keywords: mix, code, language 


\section{A. PENDAhULUAN}

Masyarakat tutur bahasa Meher adalah orang yang tinggal atau menetap di Pulau Kisar, khususnya di Desa Wonreli, Lekloor, Abusur, Lebelau, Purpura,Nomaha, dan Kotalama. Pulau Kisar merupakan salah satu pulau yang menghimpun seluruh masyarakat dari berbagai etnis/suku di seluruh wilayah Maluku Barat Daya. Kenyataan tersebut dapat dilihat pada situasi tutur yang menjadikan bahasa Meher,bahasa Oirata dan bahasa Malayu Ambon sebagai medium komunikasi. Akan tetapi dalam komunikasi sehari-hari terutama komunikasi antar-kelompok masyarakat di Wonreli biasanya digunakan bahasa Malayu Ambon dan juga bahasa Meher, bukan ketiga bahasa yang disebutkan di atas.Di sini terlihat bahwa kebutuhan masyarakat dalam menguasai bahasa Malayu Ambon merupakan hal tidak bisa dielakkan.Kalau mereka hanya menguasai bahasa Meher saja, mereka akan merasa kesulitan dalam berkomunikasi dengan orang-orang yang berdatangan dari Desa Oirata Timur dan Oirata Barat.

Berkaitan dengan bahasa sebagai alat komunikasi, seseorang di samping perlu berkomunikasi dengan sesama anggota masyarakat bahasa sekitarnya, mereka perlu juga berkomunikasi dengan anggota masyarakat bahasa lain dari daerah lain, guna memenuhi kebutuhan hidup.Dalam kepentingan komunikasi tersebut, bahasa Malayu Ambon yang paling tepat sebagai sarana penghubung (dalam komunikasi) antaretnik yang ada. Pasar Yotowawa-Wonreli merupakan gambaran yang tepat untuk menyatakan situasi heterogen.Di tempat itu pula masyarakat yang berasal dari berbagai desa di Pulau Kisar mengadakan transakasi jual beli baik dalam skala besar, menengah maupun kecil. Mereka datang dari latar belakang bahasa yang berlainan, sehingga komunikasi yang terjadi pun menggunakan bahasa yang bercampuran. Sesekali mereka memakai bahasaMalayu Ambon, kemudian bahasa Oirata, dan bahasa Meher.

Dari hal tersebut mengakibatkan terjadinya campur kode. Campur kode terjadi karena kontak bahasa dan saling ketergantungan bahasa, yang disebabkan oleh hubungan peran (siapa) dan fungsi kebahasaan (apa yang hendak dicapai). Peristiwa yang terjadi di lapangan dalam masyarakat Wonreli di pasar Yotowawa Kabupaten Maluku Barat Daya, peneliti menemukan antar penjual dengan pembeli dalam interaksi jual-beli menggunakan campur kode bahasa Malayu Ambon dengan bahasa Meher. Misalnya pada saat mereka berbicara menggunakan bahasa

Melayu Ambon (BMA) terkadang terjadi percampuran atau serpihan-serpihan bahasa daerah. Hal ini sudah dapat dikatakan terjadinya campur kode. Contoh campur kode yang antara bahasa Meher dan bahasa Malayu Ambon: Konteks pembelian terjadi antara penjual dan pembeli pada saat pembeli sementara melihatlihat barang yang akan dibelanjakannya, tiba-tiba ada ibu menawarkan kepada pembeli. 
Percakapan:

Pedagang: Nale e seng beli ikan ka?

"Ibu tidak beli ikan kah?"

Pembeli: Barang i'ine idta woira?

"Memangnya ikan satu tempat harga berapa?"

Pedagang: satu tampa 20 ribu nai $e$

"Satu tampat 20 ribu rupiah mama"

Terjadinya campur kode dalam percakapan di atas yaitu pada kata 'nale' adalah panggilan untuk ibu dalam bahasa Meher, sedangkan pada kata 'seng'. 'ka', 'tampa, 'barang' dan 'e' adalah pengaruh bahasa Melayu Ambon (BMA), dan pada kata 'i 'ine idta woira' adalah bahasa Meher. Campur kode dalam makna bahasa tersebut adalah untuk menarik perhatian pembeli agar mau membeli ikan yang ditawarkan. Berdasarkan kenyataan ini, maka masyarakat Wonreli adalah masyarakat pada umumnya sebagai penutur bahasa Meher dan saling mempengaruhi antara bahasa daerah yang satu dengan bahasa daerah yang lain atau dengan bahasa Malayu Ambon.

Disamping itu, penelitian yang dilakukan untuk meneliti campur kode bahasa daerah Meher di lingkungan pasar Yotowawa belum pernah dilakukan. Hal tersebut yang mendorong penulis untuk melakukan penelitian tentang "Campur Kode Dalam Interaksi Jual Beli di Pasar Yotowawa Kecamatan Pulau-Pulau Terselatan Maluku Barat Daya”.Tujuan Penelitian Tujuan penelitian ini adalah untuk mendeskripsikan campur kode dalam interaksi jual beli di pasar Yotowawa Kecamatan Pulau-Pulau Terselatan Kabupaten Maluku Barat Daya .

Tujuan penelitian ini adalah untuk mendeskripsikan campur kode dalam interaksi jual beli di pasar Yotowawa Kecamatan Pulau-Pulau Terselatan Kabupaten Maluku Barat Daya

\section{B. METODE PENELITIAN}

Data dalam penelitan ini berupa percakapan lisan yang muncul dari aktivitas alamiah antara penjual dan pembeli yang sedang melakukan komunikasi dan transaksi jual beli di pasar Yotowawa. Data tersebut diperoleh dalam bentuk catatan lapangan, hasil rekaman, dan hasil pengamatan.

Sumber data penelitian ini adalah masyarakat dalam hal ini penutur dan mitra tutur yang terlibat dalam komunikasi transaksi jual beli di pasar Yotowbnawa.

Untuk menganalisis data, peneliti menggunakan metode analisis data model inter aktif, seperti yang dikemukakan oleh Miles dan Huberman (1992:20). Metode ini me mpunyai beberapa tahap, yaitu :

a) Pengumpulan Data

Dalam mengumpulkan data, peneliti melakukan pengamatan langsung terhad ap interaksi jual beli di pasar Yotowawa-Wonreli Kecamatan Pulau-Pulau Ter selatan Kabupaten Maluku Barat 
b) Reduksi

Data Pada tahap ini, data-data yang dikumpulkan mulai direduksi, didentifika si, dan diberi pengkodean. Data-data yang telah diberikan pengkodean dan pe nandaan, kemudian diklasifikasikan berdasarkan bentuk dan makna campur $\mathrm{k}$ ode dalam percakapan. Penyeleksian dan pengidentifikasian merupakan kegia tan untuk menyeleksi dan mengidentifikasi data-data yang termasuk dalam c ampur kode.

Data yang tidak termasuk campur kode tidak dijadikan data dalam penelitian atau dihilangkan. Setelah itu, pengklasifikasian dilakukan dengan mengelomp okan data berdasarkan bentuk yaitu berupa kata, frasa, dan kalimat.

Contoh pemerolehan data, 01. 1

$01=$ Keterangan untuk urutan percakapan

1 = Keterangan untuk baris terdapatnya data Kode Dokumen:

DR = Data Rekaman

DCL = Data Catatan Lapangan

c) Penyajian Data

Pada tahap ini, data-data yang diklasifikasikan harus melewati proses pendesk ripsian data-data, untuk mengetahui bentuk dan makna campur kode dalam te ks percakapan bahasa Malayu Ambon dan bahasa Meher.

d) Penarikan kesimpulan

Pada tahap ini, peneliti menarik kesimpulan dan memverifikasi data selama $\mathrm{p}$ enelitian ini berlangsung. Kesempatan sementara diperoleh ketika analisis dil akukan dalam proses penelitian termasuk pada tahap reduksi, untuk setiap dat a yang telah diklasifikasikan. Sedangkan kesempatan akhir diperoleh pada tah ap akhir analisis yakni setelah melihat secara menyeluruh setiap kegiatan anal isis dan intepretasi terhadap temuan penelitian yang telah diklasifikasikan ata u dikategorikan. Jika kesimpulan mengenai bentuk dan makna campur kode d alam teks percakapan bahasa Malayu Ambon dan bahasa Meher dipandang k urang mendalam atau kurang memadai maka peneliti bisa kembali pada prose s pengumpulan data untuk memperoleh data yang lebih akurat.

\section{PEMBAHASAN}

Peristiwa campur kode terjadi karena pemakaian bahasa oleh penutur. Percampuran bahasa itu terjadi pada tuturan para pembeli dan pedagang di pasar Yotowawa. Mereka suka mencampurkanbeberapa bahasa pada setiap bertutur,baik percampuran bahasa Meher dan bahasa Malayu Ambon.Pada bagian ini peneliti membahasa mengenai permasalahan yang telah dirumuskan. Pada perumusan penelitian ini, yakni mendeskripsikan wujud atau bentuk campur kode yaitu berupa kata,

dan

klausa. 


\section{a. Bentuk Campur Kode}

Berdasarkan hasil pengamatan, ditemukan adanya bentuk campur kode dalam interaksi antar pembeli dan penjual di pasar Yotowawa berupa kata, dan frasa.

b. Campur Kode Berupa Kata

Kata sering kali kita dengar dan kita gunakan. Untuk dapat digunakan dalam kalimat atau pertuturan tertentu, maka harus dibentuk dulu menjadi sebuah kata gramatikal. Kata dalam kamus linguistik merupakan satuan bahasa yang dapat berdiri sendiri Harimurti (2008 : 110). Defenisi lain dari kata menurut Verhaar (2008:97) ialah satuan atau bentuk bebas dalam tuturan yang dapat berdiri sendiri. Kata tidak dapat dipecah menjadi bagian yang lebih kecil.

c. Campur kode bahasa Meher dengan Bahasa Melayu Ambon (BMA) yang berbentuk kata.

Campur kode bahasa Meher dengan Bahasa Melayu Ambon (BMA) di pasar Yotowawa-Wonreli dalam berkomunikasi dapat terjadi dalam situasi nonformal dalam bentuk kata. Untuk lebih jelasnya dapat dilihat sebagai berikut.

Contoh 1.

Konteks: Permintaan-penawaran terhadap harga ikan cakalang.

Pembeli: "Mama e ikan cakalang saekor harga brapa"?

(Ibu ikan cakalang satu ekor harga berapa?)

Penjual: "Kalo saekor tiga puluh ribu nona".

(Kalau satu ekor harga tiga puluh ribu nona.)

Pembeli: "Seng bisa par kurang akang harga sadiki lai ka"?

(Tidak bisa kurangi harganya sedikit?)

Penjual: "Ale mau minta brapa"?

(Anda mau harga berapa?)

Pembeli: "Dua puluh ribu jua. Bisa ka"?

(Dua puluh ribu. Bisa?)

Penjual: "Iya sudah. Wa'an"

(Iya sudah. Bisa)

(DCL.01:6)

Percakapan di atas pembeli menawarkan harga ikan cakalang kepada penjual. Maksud percakapan tersebut adalah pembeli menawarkan harga ikan cakalang lima puluh ribu untuk dua ekor ikan. Pembeli memberikan penekanan tentang harga ikan cakalang yang akan dibelinya.Percakapan tersebut terjadi antara penjual dan pembeli dikarenakan keduanya memiliki dialek yang sama.Dalam percakapan tersebut, pembeli menggunakan campur kode Bahasa MelayuAmbon dengan bahasa Meher karena pembeli ingin mengubah suasana menjadi akrab dan bersikap ramah kepada penjual agar ikan cakalang yang ingin dibelinya, mau dibeli dengan harga murah, sehingga percakapan tersebut mengalami campur kode Bahasa Melayu

Ambon dengan bahasa Meher yang ditandai dengan kata "bisa" yang dalam bahasa Meher adalah “wa'an”. Latar belakang terjadinya campur kode pada kata wa'an yaitu kesantaian dan kebiasaan penutur ketika berbicara dalam situasi 
informal. Fungsi campur kode dalam dialog tersebut adalah kebutuhan kosakata, penutur menyebutkan kata wa'an yang biasa digunakan dalam kehidupan seharihari, sehingga mitra tutur mengerti maksud dan maknanya. Batasan dan tujuan berbicara menggunakan kata wa'an yaitu untuk menyetujui dua ekor ikan cakalang kepada mitra tutur tentang sesuatu yang dimaksud, misalnya si pembeli menawarkan kepada penjual. Struktur dan kaidah negosiasi berjalan dengan baik melalui kompromi hingga mencapai kesepakatan harga di antara keduanya.

Konteks: Permintaan-penawaran terhadap kelapa.

Pembeli: "Akang bagus kaseng no're ini mama?"

(Ibu kelapa ini bagus atau tidak?)

Penjual: "Bagus nona. Itu kamareng baru nae akang saja tu".

(Bagus nona. Kemarin baru dipetik.)

Pembeli: "Kalo bagitu, sabuah harga barapa?"

(Kalau begitu, satu buah harga berapa?)

Penjual: "Tiga ribu."

(Tiga ribu rupiah.)

Pembeli: Tiga buah par beta jua.

(Tiga buah untuk saya)

(DCL. 02:1)

Penjelasan dari percakapan di atas adalah pembeli menanyakan berapa harga satu buah kelapa yang dijual. Pada percakapan tersebut pembeli tidak sengaja menggunakan percakapan yang santai dan akrab. Percakapan itu mengalami campur kode Bahasa Melayu Ambon dengan bahasa Meher. Hal ini dapat dilihat pada kalimat pertama yang dituturkan pembeli yaitu kata "no're" yang dalam bahasa Meher adalah "kelapa". Latar belakang terjadinya campur kode pada kata no're yaitu kesantaian dan kebiasaan penutur ketika berbicara dalam situasi informal.

Fungsi campur kode dalam dialog tersebut adalah kebutuhan kosakata, penutur menyebutkan benda umum yang biasa digunakan dalam kehidupan sehari-hari, sehingga mitra tutur mengerti maksud dan maknanya dengan sendirinya. Batasan dan tujuan berbicara menggunakan kata no're yaitu untuk menanyakan dan melaporkan kepada lawan tutur tentang sesuatu yang dimaksud, misalnya si pembeli melaporkan kepada penjual maksud kedatangannya untuk membeli kelapa serta pembeli menanyakan harga satu buah

kelapa yang akan dibelinya kepada penjual.

Konteks: Permintaan-penawaran terhadap sendal.

Pembeli: "Coba beta lia sandal yang itu do"

(Coba saya lihat sandal itu.)

Penjual: "Barang mau yang warna apa?"

(Mau yang warna apa?)

Pembeli: "Momohon sa jua"

(Hitam saja) 
Penjual: "Iya nai $e$ "

(Iya nona)

(DCL.03.3)

Bentuk kata dalam peristiwa campur kode antara bahasa Meher dan Bahasa Melayu Ambon dalam tuturan para pelaku di pasar Yotowaw-Wonreli pada saat pembeli menanyakan tentang warna sandal yang menimbulkan campur kode saat mengucapkan kalimat dengan mencampurkan kedua bahasa di atas, maka saat itu pula terjadi campur kode. Penanda terjadinya campur kode terletak pada kata "hitam" yang dalam bahasa Meher adalah "momohone". Latar belakang terjadinya campur kode pada kata momohone yaitu kesantaian dan kebiasaan penutur ketika berbicara dalam situasi informal. Fungsi campur kode dalam dialog tersebut adalah kebutuhan kosakata, penutur menyebutkan warna umum yang biasa digunakan dalam kehidupan sehari-hari, sehingga lawan bicara mengerti maksud dan maknanya dalam sendirinya.

Batasan dan tujuan berbicara menggunakan kata momohone yaitu untuk memberitahukan dan melaporkan kepada lawan tutur tentang sesuatu yang dimaksud, misalnya si pembeli memberitahukan kepada penjual maksud kedatangannya di toko tersebut, begitu juga dengan penjual yang hendak melaporkan kepada pembeli warna apa yang akan dibeli. Struktur dan kaidah negosiasi berjalan dengan baik melalui kompromi hingga mencapai kesepakatan harga di antara keduanya.

Konteks: Permintaan-penawaran terhadap sayur Sawi.

Pembeli: "Om, sawi ni saika brapa?"

(Om, sawi ini satu ikat harga berapa?)

Penjual: "Delapan ribu"

(Delapan ribuh rupiah)

Pembeli: "Opler Lerwol'e mahal lawang. Yang batul brapa? “

(Ya ampun mahal sekali. Yang benar berapa?)

Penjual: "Iyo e sayur ada mahal"

(Iya, sayur lagi mahal)

(DCL. 04:3)

Peristiwa campur kode yang terjadi pada kata Opler Lerwol'e tersebut merupakan campur kode dialog. Campur kode kata Opler Lerwol'e merupakan peristiwa campur kode ke dalam (intern code-mixing) karena kata Opler Lerwol'e berasal dari bahasa daerah (bahasa Meher). Kata Opler Lerwol'e memiliki arti Tuhan e yang berfungsi sebagai panggilan untuk Tuhan. Kata Opler Lerwol'e termasuk ke dalam kelas kata nomina. Pada percakapan di atas, pembeli bertutur menggunakan campur kode berwujud kata Opler Lerwol'e. Hal ini disebabkan pembeli merasa terkejut karena anggapan pembeli harga sawi tidak setinggi yang ditawarkan

penjual. 
Namun bagi penjual akan menawarkan harga berapapun tidak akan ada yang melarang. Latar belakang terjadinya campur kode pada kata Opler Lerwol'e yaitu kesantaian dan kebiasaan penutur ketika berbicara dalam situasi informal. Fungsi campur kode tersebut adalah penutur mencari jalan termudah menyampaikan maksud. Batasan dan tujuan berbicara adalah untuk menyapa seseorang jika tidak menyebutkan atau tidak diketahui namanya. Struktur dan kaidah negosiasi berjalan dengan baik melalui kompromi hingga mencapai kesepakatan harga di antara keduanya. Peristiwa campur kode didapat pada kata baju, dapat dilihat pada konteks percakapan di bawah ini.

Konteks: Permintaan-penawaran terhadap pakaian.

Penjual: "Mau beli rain warna apa?"

(Mau beli baju warna apa?)

Pembeli: "Rain warna apa e"

(Baju warna apa)

Penjual: "Warna apa, bilang saja nanti beta ambel"

(Warna apa, bilang saja nanti saya ambil).

Pembeli: "Warna apa e beta bingung e"

(Warna apa, saya bingung).

(DCL.05.2)

Peristiwa campur kode yang terjadi pada kata rain tersebut merupakan campur kode dialog. Campur kode kata rain merupakan peristiwa campur kode ke dalam (intern code-mixing) karena kata rain berasal dari bahasa daerah Kisar (bahasa Meher). Kata rain memiliki arti yaitu baju. Latar belakang terjadinya campur kode pada kata baju yaitu kebiasaan penutur ketika berbicara dalam situasi informal. Fungsi campur kode dalam dialog tersebut adalah kebutuhan kosakata, penutur menyebutkan benda umum yang biasa digunakan dalam kehidupan sehari-hari, sehingga mitra tutur mengerti maksud dan maknanya sendiri. Batasan dan tujuan berbicara menggunakan kata baju yaitu untuk memberitahukan dan melaporkan kepada lawan tutur tentang sesuatu yang dimaksud, misalnya pembeli memberitahukan kepada penjual maksud kedatangannya di toko tersebut, begitu juga dengan penjual yang hendak melaporkan kepada pembeli warna apa yang akan dibeli. Peristiwa campur kode didapat pada kata Inai pada percakapan sebagai berikut:

Konteks: Permintaan-penawaran terhadap kain.

Pembeli: "Inai, kira-kira yang bagus tu yang mana e?"

(Nona,kira-kirayangbagusituyangmana?)

Penjual: "Kalo yang bagus tu kain yang tabal. Kainnya paleng bagus"

(Kalau yang bagus itu kain tebal. Kainnya paling bagus)

Pembeli: "Oh kalo bagitu beta bali akang jua inai e"

(Oh kalau begitu saya beli sudah nona)

(DCL. 06:1) 
Peristiwa campur kode pada kata Inai merupakan peristiwa campur kode antara Bahasa Melayu Ambon dengan bahasa Meher. Kata Inai berasal dari bahasa Meher yang memiliki arti 'kata sapaan terhadap wanita yang dianggap masih muda' yang berfungsi sebagai panggilan untuk wanita. Maksud kata Inai tersebut adalah untuk menyapa seorang (gadis) yang berjualan di toko. Latar belakang terjadinya campur kode pada kata Inai yaitu kebiasaan penutur ketika berbicara dalam situasi informal. Fungsi campur kode tersebut adalah penutursebagai pembeli menghormati lawan tuturnya sebagai penjual. Batasan dan tujuan berbicara adalah untuk menyapa seseorang jika tidak menyebutkan atau tidak mengetahui namanya. Peristiwa campur kode dijumpai pada kata sapu dengan percakapan sebagai berikut:

Konteks: Permintaan-penawaran terhadap lemon.

Pembeli: "Sapu ni sakilo brapa?"

(Lemon ini satu kilo harga berapa?)

Penjual: "Tiga plima ribu"

(Tiga puluh lima ribu rupiah)

Pembeli: "Astaga mahal e seng bisa kurang sadiki lai?"

(Astaga mahalnya tidak bisa dikurangi sedikit?)

(DR. 07:1)

Peristiwa campur kode yang terjadi pada kata sapu tersebut merupakan campur kode yang dipakai dalam kehidupan sehari-hari, karena kata sapu berasal dari bahasa Meher, yang memiliki arti 'lemon' yang berfungsi sebagai ungkapan kaget atau terkejut. Maksud dari dialog di atas adalah seorang pembeli yang kaget ketika mengetahui harga lemon yang sudah semakin mahal. Latar belakang terjadinya campur kode pada kata sapu yaitu kesantaian dan kebiasaan penutur ketika berbicara dalam situasi informal. Fungsi campur kode tersebut adalah penutur menanyakan harga lemon satu kilo berapa kepada penjual.

b. Campur Kode Berupa Frasa

Frasa didefinisikan sebagai satuan gramatikal yang berupa gabungan kata yang bersifat nonpredikatif, atau lazim disebut gabungan kata yang mengisi salah satu fungsi sintaksis dalam kalimat (Chaer, 2007:222). Frasa juga dapat diartikan sebagai kelompok kata yang merupakan bagian fungsional dari tuturan yang lebih panjang (Verhaar 2008 : 291). Berikut ini merupakan contoh campur kode berupa frasa yang dipakai pembeli dan penjual pada saat berinteraksi di pasar Yotowawa-Wonreli dapatdilihat pada tabel berikut. Peristiwa campur kode dijumpai pada kata kupan kale dengan percakapan sebagai berikut:

Konteks: Penawaran terhadap ikan.

Penjual: "Mama seng beli ikan?"

(Ibu tidak beli ikan?)

Pembeli: "Seng nona e kupan kale"

(Tidak nona tidak ada uang) 
(DR. 08:2)

Peristiwa campur kode yang terjadi pada frasa kupan kale tersebut merupakan campur kode dialog. Campur kode frasa kupan kale merupakan peristiwa campur kode ke dalam (intern code-mixing) karena frasa kupan kale berasal dari bahasa Meher yang berarti 'tidak ada uang'. Maksud dari dialog tersebut adalah pembeli menawarkan kepada seorang ibu untuk membeli ikan, namun ibu tersebut mengatakan bahwa ia tidak mempunyai uang. Latar belakang terjadinya campur kode pada frasa kupan kale yaitu kesantaian dan kebiasaan penutur dalam menyebutkan 'kupan kale' menjadi 'tidak ada uang'. Fungsi campur kode tersebut adalah kebutuhan kosakata, unsur tersebut merupakan hal yang umum yang biasa digunakan untuk memberitahu mitra tutur, misalnya pembeli memberitahukan kepada penjual bahwa ia tidak mempunyai uang untuk membeli ikan. Peristiwa campur kode dijumpai pada frasa yau suke dengan percakapan sebagai berikut:

Konteks: Permintaan-penawaran terhadap pakaian.

Penjual: "Kaka ambe contoh daster kuning tu dolo"

(Kakak ambil contoh daster warna kuning itu dulu) Anak

penjual: "Akang pung tampa disusunan atas ka bawah?"

(Tempatnya disusunan atas ataukah bawah?)

Pembeli: "Beta yau suke deng daster itu"

(Saya paling suka dengan daster itu)

Penjual: "Mama mau tawar deng harga brapa, tawar saja"

(Ibu mau tawar dengan harga berapa, tawar saja)

Pembeli: "Dua plima ribu"

(Dua puluh lima ribu)

(DCL. 09:3)

Dalam penggalan percakapan di atas, pembeli menggunakan campur kode intern berupa tuturan bahasa Meher yang berbunyi yau suke. Artinya paling suka. Frasa paleng suka merupakan tuturan dari bahasa Meher yang disisipi dengan tuturan Bahasa Melayu Ambon "beta suka deng daster itu". Pembeli menggunakan campur kode disebabkan ia ingin menjelaskan seseuatu kepada penjual bahwa pembeli memang suka sekali dengan daster tersebut. Selanjutnya pada penggalan percakapan berikut berisi campur kode intern yang berupa frasa. Penjual menawarkan dagangannya kepada pembeli dengan bahasa Meher yang kadangkadang disisipi tuturan Bahasa Melayu Ambon pada saat tawarmenawar berlangsung. Peristiwa campur kode dijumpai pada frasa riwun wu'ira dengan percakapan sebagai berikut:

Konteks: Permintaan-penawaran terhadap pakaian.

Penjual: "Cari apa mari lia-lia dolo"

(Cari apa mari lihat-lihat dulu)

Pembeli: "Baju stelan par anak umur enam tahun ada kaseng e"

(Baju stelan untuk anak umur enam tahun ada atau tidak) 
Penjual: "Ada ibu. Lia-lia do, seng apa-apa"

(Ada ibu. Lihat-lihat dulu, tidak apa-apa)

Pembeli: "Kalo ini riwun wu'ira?"

(Kalau ini berapa ribu?)

Penjual: "Dua puluh ribu"

(Dua puluh ribu rupiah)

(DCL. 10:4)

Peristiwa campur kode yang terjadi pada kata riwun wu'ira tersebut merupakan campur kode dialog. Campur kode kata riwun wu'ira merupakan peristiwa campur kode ke dalam (intern code-mixing) karena kata riwun wu'ira berasal dari bahasa daerah Wonreli (bahasa Meher). Kata riwun wu'ira memiliki arti berapa ribu. Maksud kata riwun wu'ira tersebut adalah untuk menanyakan harga kepada penjual di toko. Dalam penggalan percakapan tersebut merupakan tuturan antara penjual dengan pembeli dalam tawar-menawar harga dengan menggunakan campur kode dengan maksud penjual memberikan dengan harga yang murah, seperti dalam tuturan 'riwun wu'ira'.

Latar belakang terjadinya campur kode pada frasa riwun wu'ira yaitu kesantaian dan kebiasaan penutur dalam menyebutkan riwun wu'ira menjadi harga berapa. Fungsi campur kode tersebut adalah kebutuhan kosakata, unsur tersebut merupakan hal yang umum yang biasa digunakan untuk memberitahu mitra tutur, misalnya pembeli menanyakan harga baju stelan anak umur enam tahun kepada penjual dan penjual menjawabnya bahwa satu pasang harganya dua puluh ribu rupiah. Peristiwa tutur lain juga ditemukan peristiwa campur kode bahasa Meher dan bahasa Melayu Ambon pada tuturan pembeli pada tuturan bentuk frasa.

Konteks: Permintaan-penawaran terhadap sayur kangkung.

Pembeli: "Kangkung saika brapa om?"

(Kangkung satu ikat harga berapa om?)

Penjual: "Tujuh ribu”

(Tujuh ribu rupiah)

Pembeli: "Lima ribu bisa k"

(Lima ribu bisa, tidak?)

Penjual: "Ini akang pung harga sudah. Kanyadi"

(Ini sudah harganya. Tidak jadi)

(DR. 11:4)

Percakapan di atas merupakan kegiatan jual beli yang dilakukan oleh penjual dan pembeli di pasar Yotowawa-Wonreli pada lapak penjualan sayur. Peristiwa tutur tersebut mengalami peristiwa campur kode, yaitu pada tuturan pembeli yang tanpa sengaja mencampurkan kode bahasa Melayu Ambon dan bahasa Meher. Hal tersebut terlihat pada tuturan "Seng bisa". Ini akang pung harga sudah. Campur kode yang terdapat dalam kalimat tersebut yaitu bentuk frasa bahasa Meher Kanyadi. Dikatakan ke dalam proses penyisipan berwujud frasa karena yang disisipkan merupakan kelompok kata yang terdiri dari dua kata. Latar belakang terjadinya 
campur kode pada kata kanyadi yaitu kebiasaan penutur ketika berbicara dalam situasi informal.

Fungsi campur kode dalam dialog tersebut adalah kebutuhan kosakata, penutur berbicara secara umum yang biasa digunakan dalam kehidupan sehari-hari, sehingga mitra tutur mengerti maksud dan maknanya senndiri. Batasan dan tujuan berbicara menggunakan kata kanyadi yaitu untuk memberitahukan dan melaporkan kepada mitra tutur tentang sesuatu yang dimaksud, misalnya pembeli menanyakan harga kangkung satu ikat kepada penjual, begitu juga dengan penjual yang hendak menjawab pertanyaan pembeli yaitu harga kangkung satu ikat tujuh ribu rupiah. Pembeli pun menawarkan harga kangkung tersebut menjadi lima ribu rupiah, namun penjual tetap mempertahankan harga jualnya di pasar dengan mengatakan kepada pembeli bahwa kanyadi yang dalam bahasa Meher, dan bahasa Melayu Ambon artinya seng bisa. Peristiwa tutur lain juga ditemukan peristiwa campur kode bahasa Meher dan bahasa Melayu Ambon pada tuturan pembeli pada tuturan bentuk frasa.

Konteks: Permintaan-penawaran terhadap sayur kangkung.

Pembeli: "Mama, kangkung wukida wuirpe?"

(Kangkung satu ikat harga berapa?)

Penjual: "Satu ika lima ribu"

(Satu ikat lima ribu rupiah)

Pembeli: Oh, dua ika par beta jua e

(Oh, dua ikat untuk saya)

Penjual: Iya nona.

(DR. 12:1)

Peristiwa campur kode yang terjadi pada frasa wukida wuirpe tersebutmerupakan campur kode dialog. Campur kode frasa wukida wuirpe merupakan campur kode ke dalam (intern code-mixing) karena frasa wukida wuirpe berasal dari bahasa Meher dan termasuk frasa nomina. Frasa wukida wuirpe memiliki arti 'satu ikat berapa?' yang berfungsi sebagai pertanyaan untuk mengetahui harga sayur. Peristiwa tutur lain juga ditemukan peristiwa campur kode bahasa Meher dan bahasa Melayu Ambon pada tuturan pembeli pada tuturan bentuk frasa.

Konteks: Permintaan-penawaran terhadap ikan.

Pembeli: "Mame, i'in satu tampa brapalah?"

(Ibu, ikan satu tempat harga berapa?)

Penjual: "Spuluh ribu nona e"

( Sepuluh ribu nona)

Pembeli: "Beta satu tampa jua mame"

(Ibu, satu tempat untuk saya)

(DCL. 13:1)

Peristiwa campur kode yang terjadi pada frasa 'Mame i'in satu tampa barapalah' tersebut merupakan campur kode dialog. Campur kode frasa Mame i'in merupakan 
campur kode ke dalam (intern code-mixing) karena frasa Mame i'in berasal dari bahasa Meher dan termasuk frasa nomina. Frasa Mame i'in satu tampa barapalah memiliki arti 'mama ikan satu tampa brapa' yang berfungsi sebagai pertanyaan untuk mengetahui harga ikan. Latar belakang terjadi campur kode pada frasa Mame i'in yaitu kesantaian dan kebiasaan penutur dalam menyebutkan 'mama, ikan' menjadi 'Mame i'in' karena penutur biasa menggunakan bahasa Meher dalam kehidupan sehari-hari.

Fungsi campur kode tersebut adalah kebutuhan kosakata. Penutur menunjukkan keakraban dalam situasi santai kepada lawan tutur. Batasan dan tujuan berbicara adalah untuk menanyakan kepada lawan tutur, misalnya pembeli menanyakan harga ikan kepada penjual dan penjual menjawab harga ikan sepuluh ribu. Peristiwa tutur ditemukan peristiwa campur kode bahasa Meher dan bahasa Melayu Ambon pada tuturan pembeli pada tuturan bentuk frasa.

Konteks: Permintaan-penawaran terhadap cili.

Pembeli: "Mama, cili satu tampa harga brapa?"

(Ibu, cabai satu tempat harga berapa?)

Penjual: "Hupida riun wulima nona e"

(Satu tempat lima ribu rupiah nona)

Pembeli: "Kal bagitu beta bali satu tampa jua"

(Kalau begitu saya beli satu tempat)

Penjual: "iya nona"

(iya nona)

(DR. 14:2)

Peristiwa campur kode yang terjadi pada klausa Hupida riun wulima tersebut merupakan campur kode dialog. Campur kode kalimat Hupida riun wulima merupakan peristiwa campur kode ke dalam (intern code-mixing) karena klausa Hupida riun wulima berasal dari bahasa Meher, yang memiliki arti 'satu tumpuk lima ribu nona'. Latar belakang terjadinya campur kode pada kalimat Hupida riun wulima yaitu kesantaian dan kebiasaan penutur dalam menyebutkan 'Hupida riun wulima' menjadi 'satu tumpuk lima ribu'. Fungsi campur kode tersebut adalah membicarakan topik tertentu, yaitu pembeli menanyakan harga cili yang diinginkannya dengan bertanya kepada penjual. Batasan dan tujuan berbicara adalah untuk menanyakan kepada mitra tutur, misalnya pembeli menanyakan harga cili satu tempat kepada penjual.

Konteks: Penawaran terhadap pembeli.

Penjual: "Mama, beli ikan?"

(Ibu, beli ikan?)

Pembeli: "Ainu'u kupan kale"

(Saya tidak punya uang)

Penjual: "Hupida riwan idweli mehe mama" 
(Satu tempat sepuluh saja ibu)

(DCL. 15:2.3)

Peristiwa campur kode yang terjadi pada klausa 'Ainu'u kupan kale' dan 'Hupida riwan idweli mehe mame' tersebut merupakan campur kode ke dalam (intern code-mixing) karena klausa 'Ainu'u kupan kale' dan 'Hupida riwan idweli mehe mame' tersebut berasal dari bahasa Meher. Kalimat 'Ainu'u kupan kale' memiliki arti 'saya tidak punya uang' dan berfungsi untuk menjawab tawaran dari penjual ikan. Sedangkan pada klausa 'Hupida riwan idweli mehe mame' memiliki arti 'satu tumpuk sepuluh ribu saja mama', dengan fungsi untuk memberitahukan kepada pembeli bahwa ikan satu tempat hanya sepuluh ribu. Maksud dari dialog tersebut adalah seorang penjual ikan menawarkan kepada pembeli untuk membeli ikan yang harganya sepuluh ribu, tetapi pembeli itu tidak membeli karena tidak punya uang. Peristiwa campur kode dijumpai pada kalimat Riwun idweli wulima nyong e dengan percakapan berikut.

Konteks: Permintaan-penawaran terhadap sopi.

Pembeli: "Mama sopi satu botol harga brapa?"

(Ibu sopi satu botol harga berapa?)

Penjual: "Riwun idweli wulima nyong e"

(Lima belas ribu)

(DCL. 16:2)

Peristiwa campur kode yang terjadi pada klausa 'I'd weli wulima nyong e' tersebut merupakan campur kode dialog. Campur kode klausa 'I'd weli wulima nyong e' merupakan peristiwa campur kode ke dalam (intern code-mixing) karena klausa 'I'd weli wulima berasal dari bahasa Meher dengan artinya adalah 'lima belas ribu'. Maksud dari dialog tersebut adalah pembeli menanyakan kepada penjual bahwa sopi satu botol berapa harganya, dan penjual menjawab satu botol harganya lima belas ribu.

Peristiwa campur kode dijumpai pada klausa 'Jut woro'o rahuwulima mame' dengan percakapan berikut.

Konteks: Permintaan-penawaran terhadap kain tanah.

Pembeli: "Mama kalo kain tanah ni harga brapa?"

(Ibu kalau kain tanah ini harga berapa?)

Penjual: “Jut woro'o rahuwulima nona e"

(Dua juta lima ratus ribu nona)

Pembeli: "Harga seng bisa kurang sadiki lai ka?"

(Harganya tidak bisa dikurangi sedikit?)

Penjual: "Kan bis" (Tidak bisa)

(DR. 17:2)

Peristiwa campur kode yang terjadi pada klausa Jut woro'o rahuwulima nai'e tersebut merupakan campur kode dialog. Campur kode kalimat Jut woro'o 
rahuwulima nai'e merupakan peristiwa campur kode ke dalam (intern code-mixing) karena klausa Jut woro'o rahuwulima nai'e berasal dari bahasa Meher dengan artinya adalah 'dua juta lima ratus nona'. Maksud dari dialog tersebut adalah pembeli menanyakan kepada penjual bahwa kain tenun berapa harganya, dan penjual menjawab dua juta lima ratus ribu. Latar belakang terjadinya campur kode pada klausa tersebut yaitu kebiasaan penutur dalam menyebutkan 'harga dua juta lima ratus ribu nona' menjadi 'Jut woro'o rahuwulima nai'e' karena penutur biasa menggunakan bahasa Meher dalam kehidupan sehari-hari. Fungsi campur kode tersebut adalah membicarakan topik tertentu, yaitu pembeli bertanya harga kain tenun dan penjual menjawab harganya dua juta lima ratus ribu. Pembeli bertanya kembali apakah harga kain tenun tersebut tidak bisa dikurangi harganya namun penjual menjawab bahwa harganya tidak bisa dikurangi lagi.

\section{KESIMPULAN}

Berdasarkan analisis data yang telah dideskripsikan, maka dapat ditarik beberapa kesimpulan sebagai berikut :

1. Bentuk campur kode dalam tuturan interaksi jual-beli di pasar Yotowawa Wonreli, yaitu campur kode intern berwujud kata dan frasa.

a) Bentuk campur kode berwujud kata, seperti wa'an, no'ore, momohone, opler lerwole, rain, inai, sapu, kanyadi, mame , i'in.

b) Bentuk campur kode berwujud frasa, kupan kale, yau suke, wukida wuirpe.

2. Faktor penyebab penjual dan pembeli menggunakan campur kode dari bahasa Malayu Ambon yang disisipi dengan tutur bahasa Meher. Hal ini terjadi karena antara pembeli dan penjual sama-sama menggunakan tuturan bahasa Malayu Ambon maupun bahasa Meher. Tuturan bahasa Meher yang disisipkan dalam tuturan bahasa Malayu Ambon, seperti wa'an, no'ore, momohone, opler lerwole, rain, inai, sapu, kupan kale, yau suke, riwun wu'ira, kanyadi, wukida wuirpe, mame ,i'in, hupida riun wulima, hupida riwun idweli mehe, i'd weli wulima, dan jut wo'ro rahuwulima. Dengan campur kode ini penjual ingin menerangkan kepada pembeli dengan berbagai macam ragam bahasa agar pembeli mengerti maksud yang diungkapkan penjual. Percakapan ini terjadi pada saat pembeli menawarkan sesuatu yang ingin dibeli kepada penjual yang latar belakang bahasa aslinya

Meher. 
Campur Kode dalam Interaksi Jual Beli di Pasar Yotowawa-Wonreli Kecamatan Pulau-Pulau Terselatan Kabupaten Maluku Barat Daya

\section{DAFTAR PUSTAKA}

Aslinda dkk. 2007. Pengantar Sosiolinguistik. Bandung :Refika Aditama

Chaer, Abdul. 1983. Pengantat Awal Sosiolinguistik, Teori dan Problem. Surakarta: Henary Offset.

Chaer, Abdul dan Leoni Agustina. 2004. Sosiolinguoistik Suatu Pengantar. Jakarta: PT. Rineka Cipta.

Gunawan . 2013. Metode Penelitian Kualitatif (Teori dan Praktik). Jakarta: PT BumiAksara

Hidayat, Asep Ahmad. 2006. Filsafat Bahasa: Mengungkapkan Hakikat Bahasa, Makna, dan Tanda. Bandung : PT Remaja Rosdakarya. 
Campur Kode dalam Interaksi Jual Beli di Pasar Yotowawa-Wonreli Kecamatan Pulau-Pulau Terselatan Kabupaten Maluku Barat Daya 